\title{
Stage IIIA Anal Cancer AJCC v8
}

National Cancer Institute

\section{Source}

National Cancer Institute. Stage IIIA Anal Cancer A/CC v8. NCI Thesaurus. Code C133801.

Stage IIIA includes: (T1, N1, M0); (T2, N1, M0). T1: Tumor $2 \mathrm{~cm}$ or smaller. T2: Tumor

larger than $2 \mathrm{~cm}$ but equal to or smaller than $5 \mathrm{~cm}$. N1: Metastasis in inguinal,

mesorectal, internal iliac, or external iliac nodes. M0: No distant metastasis. (AJCC 8th ed.) 